\title{
Silver Nanoparticle Adsorption to Soil and Water Treatment Residuals and Impact on Zebrafish in a Lab-scale Constructed Wetland
}

\author{
Angela Ebeling, Victoria Hartmann, Aubrey Rockman, Andrew Armstrong, \\ Robert Balza, Jarrod Erbe, Daniel Ebeling \\ Biology, Chemistry, Biochemistry Departments, Wisconsin Lutheran College, Milwaukee, WI, USA \\ Email: angela.ebeling@wlc.edu
}

Received April, 2013

\begin{abstract}
Nanoparticles $(<100 \mathrm{~nm})$ are becoming more prevalent in residential and industrial uses and may enter the environment through wastewater. Although lab studies have shown that nanoparticles can be toxic to various organisms, limited research has been done on the effects of nanoparticles in the environment. Environmental conditions such as $\mathrm{pH}$ and ionic strength are known to alter the biotoxicity of nanoparticles, but these effects are not well understood. The objectives of this research were to determine the impacts of silver nanoparticles (AgNP) on zebrafish in the pseudo-natural environment of a lab-scale constructed wetland, and to investigate wastewater remediation through soil and water treatment residual (WTR) adsorption of AgNPs. Concurrently, the effect of particle size on AgNP sorption was examined. Researchers exposed adult zebrafish in a lab-scale constructed wetland to concentrations of AgNP ranging from $0-50 \mathrm{mg}$ $\mathrm{AgNP} / \mathrm{L}$ and compared them to negative controls with no silver exposure and to positive controls with exposure to silver nitrate. The results suggest that aggregated AgNP do not impact zebrafish. Separately, sorption experiments were carried out examining three media - a wetland soil, a silt loam soil, and a WTR - in their capacity to remove AgNPs from water. The silt loam retained less AgNPs from solution than did the wetland soil or the WTR. In the WTR AgNPs were associated with sand size particles $(2 \mathrm{~mm}-0.05 \mathrm{~mm})$, but in the wetland soil and silt loam, approximately half of the AgNPs were associated with the sand-sized particles, while the rest were associated with silt sized $(\sim 0.05 \mathrm{~mm})$ or smaller particles. The larger sorption capacity of the wetland soil and WTR was attributed to their higher carbon content. The sorption data indicate that AgNPs adsorbed to soil and WTRs and support the idea that natural and constructed wetlands can remove AgNPs from wastewater.
\end{abstract}

Keywords: Silver Nanoparticles; Soil; Water Treatment Residuals; Constructed Wetland; Zebrafish; Remediation

\section{Introduction}

Sufficient, clean, safe drinking water is increasingly scarce in many parts of the world [1-4]. Pollutants such as excess nutrients, particulates, and pathogens are known to cause environmental as well as human health problems [5-12]. Conventional and natural methods can effectively remediate wastewater of these types of pollutants [13-15]. Other pollutants such as pharmaceuticals (hormones, anti-depressants) and nanomaterials (materials less than $100 \mathrm{~nm}$ in at least one dimension [16]) in wastewater are becoming more common [17-21]. For example, nanoparticles are becoming more prevalent in residential use (e.g. sunscreen, textiles), medical applications (e.g. wound treatment), industry (e.g. sensors and solar cells), and environmental remediation [22-25]. As a result, nanoparticles are able to enter the environment via wastewater or improper disposal $[16,19,25]$. Unfortu- nately, little is known about the removal of these new types of pollutants using conventional or natural wastewater treatment methods.

Numerous studies have shown that many nanomaterials, including silver nanoparticles (AgNPs), have toxic effects on organisms (zebrafish, medaka, rainbow trout, crucian carp, flathead minnow [26]; rainbow trout [27]; bacteria [28]; zebrafish embryos [29]; plants [30]; zebrafish, microalga, water flea [31]; bacteria [32]). Both engineered and natural nanoparticles play important roles in the health of terrestrial and aquatic ecosystems [33-35]. Toxicity of metal nanoparticles is well known in laboratory settings as indicated in the previously cited studies, but the fate of nanoparticles in the environment and the potential for bioaccumulation is unclear and complicated $[16,22,36]$.

Natural wetlands are known to have important roles in 
wastewater remediation [37] and constructed wetlands have been increasingly been used to remove pollutants $[13,15]$. The use of natural media (e.g. soil) as well as engineered or recycled media (e.g. water treatment residuals, WTRs) could improve the effectiveness of the natural wastewater treatment and these media could have the potential to remove nanoparticles as well. The objectives of this research were to determine the effectiveness of several media (two soils and a water treatment residual) on AgNP removal from solution and to investigate AgNP effects on zebrafish in a (simulated) natural setting (lab-scale constructed wetland).

\section{Materials and Methods}

\subsection{General}

In general, two main experiments were conducted. The first experiment used three media to investigate the sorption of AgNPs out of wastewater: wetland soil, silt loam soil, and WTRs (waste product of drinking water treatment process). The second experiment investigated the effect of AgNPs on zebrafish (Danio rerio) living in the "natural" environment of a lab-scale constructed wetland.

\subsection{Sorption Experiments}

The sorption study was modeled after sorption experiments used to investigate phosphorus sorption to soil or water treatment residuals [38-40]. Three media were shaken with various concentrations of AgNPs in solution and the amount of AgNPs remaining in the solution after an equilibration time was measured.

All three media were sent to the Soil and Plant Analysis Lab in Madison, WI for elemental analysis (total minerals by Inductively Coupled Plasma Optical Emission Spectrometry, total $\mathrm{N}$ by Total/Kjeldahl, and total $\mathrm{C}$ by LECO CNS-2000 analyzer) and particle size analysis (hydrometer method). A wetland soil was used because this sorption experiment was designed to be compared with the constructed wetland study explained in the following section. The wetland soil was used in both the sorption study and in the constructed wetland and was obtained from Certified Products, New Berlin, WI (Black Topsoil: http://www.certifiedproductswi.com/). The second medium, a silt loam soil (Plano silt loam, fine-silty, mixed, superactive, mesic, typic arguidoll) was chosen because it represents a typical soil in Wisconsin. The third medium, WTR, was chosen because it has previously been shown to have the ability to remove phosphorus from wastewater and could be used in constructed wetlands for the removal of that nutrient [41]. If this material could also be used to remove AgNPs, it would provide an even greater incentive to beneficially reuse the material as an amendment to help clean wastewater.
Little research has been done on the effects of WTRs on organisms in the environment [38], so to establish that these WTRs would not induce mortality, preliminary laboratory experiments using Escherichia coli and native soil bacteria were conducted and gave no evidence that moderate levels of WTRs $(0.05 \mathrm{~g} \mathrm{WTR} / \mathrm{ml})$ negatively impact bacterial growth (data not shown). The nanoparticles used in the sorption experiment were $10 \mathrm{~nm}$ monodispersed silver nanoparticles in $2 \mathrm{mM}$ sodium citrate buffer obtained from Nano Composix (10 nm citrate NanoXact Silver, JMW1148).

To conduct the sorption experiment, $0.5 \mathrm{~g}$ (dry weight) of each medium was weighed into $15 \mathrm{ml}$ conical tubes. Then $10 \mathrm{ml}$ of AgNP solution was added to each tube. Five concentrations of silver nanoparticles were used: 0 , 6, 15, 30, and $60 \mathrm{mg} A g N P / L$. The conical tubes were capped and shaken for 18 hours at $60 \mathrm{rpm}$ on a Fotodyne Orbit shaker (Lab-Line Instruments, Inc. Model Number 3520 ) at $23^{\circ} \mathrm{C}$ (room temperature). Each trial was replicated three times. After the 18 hour equilibration time, the supernatant in each tube was sampled three times -2 $\mathrm{ml}$ was removed after $30 \mathrm{~s}$ of particle settling, after 2 hours of particles settling, and after centrifuging at 2500 rpm for $10 \mathrm{~min}$ (IEC Centra-7R Refrigerated Centrifuge, S.N. 23601916). The supernatant was sampled at these times, because one objective in this research was to investigate AgNPs affinity for adsorbing to different size particles. According to Stoke's Law

$$
v_{s}=\frac{\left(\rho_{p}-\rho_{f}\right) g^{2} d_{p}}{18 u}
$$

where $\mathrm{v}_{\mathrm{s}}$ is the particle settling velocity, $\rho_{\mathrm{p}}$ is the density of the particles, $\rho_{\mathrm{f}}$ the density of the fluid, $g$ the acceleration due to gravity, $d_{p}$ the diameter of the particle, and $u$ the fluid viscosity, this equation predicts that sand size particles will settle after about $40 \mathrm{~s}$ (thus any AgNP measured in the supernatant would be either soluble, or adsorbed to silt or clay sized particles), silt size particles will settle after approximately 2 hours (thus any AgNP measured in the supernatant after 2 hours would be soluble or adsorbed to clay size particles), and after centrifuging all particles would be removed from the supernatant (and any AgNPs measured would be in solution) $[42,43]$. Using this method to determine particle size is based on an empirical method and cannot be used to accurately define the particle size [43], but for this research these sampling times give a rough estimation of the size of the particles with which AgNPs were associated.

A modified digestion method was used to quantify the amount of silver in the supernatants [44,45:EPA SW 846Method 3050B]. To each $2 \mathrm{ml}$ supernatant sample, 1 $\mathrm{ml}$ of $6 \mathrm{M}$ nitric acid was added using a repeat pipetter (Eppendorf, Repeater Plus, 2849689). The samples were placed into a water bath at $90^{\circ} \mathrm{C}$ for one hour to digest 
before measurement of elemental silver on a Perkin Elmer AAnalyst 200 Atomic Absorption Spectrometer (S/N 20054062503). Silver nitrate $\left(\mathrm{AgNO}_{3}\right.$, Fischer Chemicals, Lot number 041796) was used to make standards. Samples and $\mathrm{AgNO}_{3}$ standards were analyzed using a silver detection lamp (PerkinElmer Lumina Hollow Cathode Lamp, P/N N305-0120, S/N 030211-020140).

\subsection{Lab-Scale Constructed Wetland Experiment}

In this experiment, AgNP effects on zebrafish were investigated in a lab-scale constructed wetland monitored in a climate controlled greenhouse. Because most previous studies of AgNP impacts on organisms have taken place in petri dishes or other aseptic environments, this experiment was designed to investigate AgNP impacts in a more natural setting. Each AgNP treatment was applied in a separate constructed wetland that consisted of a five gallon bucket in which wetland media was placed in a polyvinyl chloride (PVC) column (to keep the media separate from the zebrafish).

The five gallon bucket contained wetland media in a $11.4 \mathrm{~cm}$ (4.5 in) (diameter) by $38.1 \mathrm{~cm}$ (15 in) (height) capped PVC column (Figure 1). To make the wetland media, each PVC column was filled with $20 \mathrm{~cm}$ of 1.3 $\mathrm{cm}(0.5 \mathrm{inch})$ washed gravel and $8 \mathrm{~cm}$ of wetland soil $(\sim 800 \mathrm{~g})$. The gravel and wetland soil were obtained from Certified Products, New Berlin, WI. Each bucket also contained a circulating pump (Mini-Jet 404, Marineland) and a small amount of aquarium gravel to support the column from tipping over. A $1.3 \mathrm{~cm}$ (0.5 inch) diameter tube was directed from the pump to a split which distributed the water pressure; the split was controlled with a pinch clamp with one half dispersing oxygenated water back to the fish and the other half entering the top of the column. The column had multiple $1.3 \mathrm{~cm}(0.5 \mathrm{inch})$

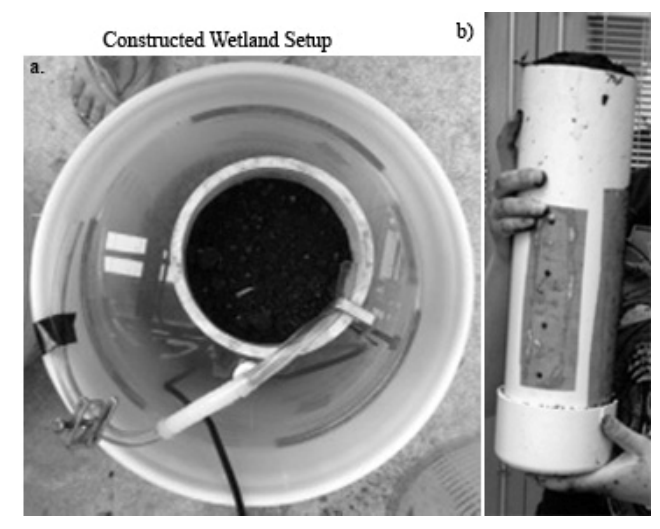

Figure 1. Photos of (a) the top view of the lab-scale constructed wetland: five gallon bucket with soil column in the middle and tubing along the side connected to the circulating pump and (b) the side view of the soil column: $20 \mathrm{~cm}$ of gravel on the bottom and $8 \mathrm{~cm}$ of wetland soil at the top; mesh covering $1.3 \mathrm{~cm}$ holes. holes covered with mesh to allow water to be circulated from the bucket through the soil media (Figure 1(b)). This allowed AgNPs to have contact with the soil media (which is more similar to a natural environment than having zebrafish and nanoparticles in isolation).

Each bucket contained $12 \mathrm{~L}$ of deionized (DI) water with $3.8 \mathrm{~g}$ of ocean salt and $0.5 \mathrm{~g}$ of $\mathrm{pH} 7$ buffer. There were six treatments: negative control (ocean salt and no AgNP), negative control with dispersing agent (ocean salt with $2 \mathrm{mg} / \mathrm{L}$ Tide and no AgNP), and $15 \mathrm{mg} \mathrm{AgNP/L}$ (< $90 \mathrm{~nm}$ powder, mKnano), $25 \mathrm{mg} \mathrm{AgNP/L,} 50 \mathrm{mg}$ $\mathrm{AgNP} / \mathrm{L}$, and a positive control (15 $\left.\mathrm{mg} \mathrm{AgNO}_{3} / \mathrm{L}\right)$. Each AgNP treatment also had ocean salt and $2 \mathrm{mg} / \mathrm{L}$ Tide. The liquid laundry detergent Tide (Tide ${ }^{\circledR}$ Active with Febreze) was used as the dispersing agent for the AgNP powder, both because it was shown to be an effective dispersing agent in preliminary trials and because it mimicked one of the ways nanoparticles might enter wastewater (i.e. through residential laundry). Tide is a commercial laundry detergent commonly used in American households. After the constructed wetland was prepared (PVC column of wetland media, circulating pump, and treatment addition), five zebrafish, three female and two male, were placed into each bucket. The zebrafish were sexually mature fish of at least 2 months of age and supplied from Aquatics Unlimited (Greenfield, WI). The constructed wetlands were placed in a temperature regulated greenhouse room kept at $27 \pm 5^{\circ} \mathrm{C}$. The temperature, $\mathrm{pH}$, silver content of the water, and the health of the fish were monitored daily. The fish were kept in the constructed wetland exposed to AgNP for one week. The zebrafish were fed daily with Zeigler adult zebrafish diet (Zeigler product \#AH271). Institutional approval from the on-campus Animal Care and Use Committee was received before carrying out this research.

At the end of the week remaining live zebrafish were euthanized and a soil sample taken from the wetland media column at 3 depths (surface, center, bottom). The water and soil samples were digested with $6 \mathrm{M}$ nitric acid and analyzed with atomic absorption spectroscopy using the method described above in the AgNP sorption experiment section. For the water samples, $2 \mathrm{ml}$ of sample were digested with $1 \mathrm{ml}$ of $6 \mathrm{M}$ nitric acid. The soil samples were air dried after which $0.5 \mathrm{~g}$ of soil was digested with $2 \mathrm{ml}$ of $6 \mathrm{M}$ nitric acid and $10 \mathrm{ml}$ of $2 \mathrm{mM}$ citrate solution before elemental silver analysis on the AA. This experiment was replicated three times in consecutive weeks.

\section{Results and Discussion}

\subsection{Physical and Chemical Characteristics of the Media}

Chemical and physical analysis of the media used in both 
the sorption experiment and lab-scale constructed wetland experiment is reported in Table 1. The texture of the wetland soil, silt loam soil, and WTR was sandy loam, silt loam, and loamy sand, respectively. The wetland soil and WTR had very similar sand content $(71 \%$ and $75 \%$, respectively), the same silt content $(23 \%)$, and correspondingly different clay content $(6 \%$ and $2 \%$, respectively). The wetland soil had the highest carbon content $(332,600 \mathrm{mg} / \mathrm{kg})$ as would be expected. The WTR had lower carbon content $(76,800 \mathrm{mg} / \mathrm{kg})$, and the silt loam had the lowest $(19,850 \mathrm{mg} / \mathrm{kg})$. These media had varying nutrient contents, e.g. the wetland soil had the highest nitrogen and phosphorus content $(24,320 \mathrm{mg} \mathrm{N} / \mathrm{kg}$ and $967 \mathrm{mg} \mathrm{P} / \mathrm{kg}$ ) but the lowest magnesium and aluminum content (2782 $\mathrm{mg} \mathrm{Mg} / \mathrm{kg}$ and $4035 \mathrm{mg} \mathrm{Al} / \mathrm{kg}$ ). The WTR had aluminum content an order of magnitude higher than the silt loam (110,532 vs. $15,480 \mathrm{mg} \mathrm{Al} / \mathrm{kg}$, respectively) and two orders of magnitude higher than the wetland soil (4035 mg Al/kg). This was not surprising because aluminum salts are used as coagulants in water treatment.

\subsection{Sorption Experiments}

The purpose of the sorption experiments was to determine if the media had the ability to remove AgNPs from water as well as to investigate which soil particle size (sand, silt, or clay) AgNPs adsorb too preferentially. The horizontal axes in Figure 2 are the initial AgNP concentrations in the solution shaken with each medium (mg AgNP/L solution). The vertical axes are the mass of AgNP adsorbed per mass of medium (mg AgNP/kg medium). Straight lines indicate that the medium still has the ability adsorb more AgNP; a curve bending to the right (becoming horizontal) indicates that the medium

Table 1. Selected properties of the three media used in the sorption and constructed wetland experiments.

\begin{tabular}{cccc}
\hline Parameter $^{\mathrm{a}}$ & Silt Loam Soil & Wetland Soil & WTR \\
\hline $\mathrm{C}(\mathrm{mg} / \mathrm{kg})$ & 19850 & 332600 & 76800 \\
$\mathrm{~N}(\mathrm{mg} / \mathrm{kg})$ & 1818 & 24320 & 4068 \\
$\mathrm{P}(\mathrm{mg} / \mathrm{kg})$ & 389 & 967 & 788 \\
$\mathrm{Ca}(\mathrm{mg} / \mathrm{kg})$ & 3459 & 23954 & 31010 \\
$\mathrm{Mg}(\mathrm{mg} / \mathrm{kg})$ & 4263 & 2728 & 12901 \\
$\mathrm{~S}(\mathrm{mg} / \mathrm{kg})$ & 199 & 11705 & 1655 \\
$\mathrm{Fe}(\mathrm{mg} / \mathrm{kg})$ & 18830 & 14504 & 6614 \\
$\mathrm{Al}(\mathrm{mg} / \mathrm{kg})$ & 15480 & 4035 & 110532 \\
$\mathrm{Sand}(\%)$ & 19 & 71 & 75 \\
$\mathrm{Silt}(\%)$ & 63 & 23 & 23 \\
Clay $(\%)$ & 18 & 6 & 2 \\
Soil Texture & Silt Loam & Sandy Loam & Loamy Sand \\
\hline
\end{tabular}

${ }^{\mathrm{a}}$ All minerals are total elemental; $\mathrm{C}$ by LECO; $\mathrm{N}$ by Kjeldahl; $\mathrm{P}, \mathrm{Ca}, \mathrm{Mg}, \mathrm{S}$, $\mathrm{Fe}$, and $\mathrm{Al}$ by ICP-OES. Sand, silt, and clay percentages were determined by the hydrometer method. All analyses were completed at the Soil and Plant Analysis Lab, Madison, WI. had a diminished capacity to adsorb more AgNP, thus leaving more in solution. This occurs because the sorption sites gradually become filled. None of the media in this experiment show much curve (Figures 2(a), (b), (c)), indicating that they all have the potential to adsorb more AgNPs from solutions with concentrations of AgNPs higher than the highest used in this study $(60 \mathrm{mg}$ AgNP/L). However, both the wetland soil and the WTR adsorbed a much greater total mass of AgNPs per mass of media than did the silt loam soil (1250 and $1000 \mathrm{mg}$ AgNP/kg vs. $220 \mathrm{mg} \mathrm{AgNP/kg}$, respectively). The average percentage of AgNP adsorbed to all size particles at the highest initial solution concentration (60 mg AgNP/L) in the wetland soil, WTR, and silt loam soil (determined by subtracting the concentration of AgNP in solution after shaking from the initial concentration of AgNP in the shaking solution and dividing by the initial concentration) was $100 \%, 81 \%$, and $18 \%$, respectively (Table 2). This data also shows that the silt loam soil adsorbed approximately half of the total AgNP from the lowest initial concentration (49\%) and progressively adsorbed a smaller percentage as the initial AgNP concentration increased. The WTR showed a similar phenomenon adsorbing $93 \%$ of the total AgNP available at lowest initial concentration decreasing to adsorbing $81 \%$ of the total AgNP in solution at the highest initial concentration. These results suggest that the wetland soil and the WTR are able to remove substantial amounts of AgNP from water.

Looking more closely at the impact of the size of the media particles in removing nanoparticles, the data show that all of AgNPs were associated with sand size particles in the WTR (Figure 2(c)). The data points for each sampling time (30 s, 2 hrs, and after centrifuging) of the WTR are very similar, indicating that little more AgNPs were removed with the smaller sized particles. However, data from the silt loam and wetland soils show that approximately half of the AgNPs were removed from the $60 \mathrm{mg}$ AgNP solution after $30 \mathrm{~s}$ of settling (100 out of $220 \mathrm{mg} \mathrm{AgNP} / \mathrm{kg}$ and 680 out of $1250 \mathrm{mg} \mathrm{AgNP} / \mathrm{kg}$, respectively) (Figures 2(a) and (b)). A similar effect was seen at the lower initial AgNP solution concentrations. This indicates that about half of the AgNP in solution were adsorbed to sand sized particles and about half of the AgNP were adsorbed to silt and clay size particles.

The wetland soil and WTR differ from the silt loam soil in that they both have very similar sand content ( $>$ $70 \%$ sand) and both have a higher total carbon value compared to the silt loam soil (Table 1). The sand content cannot be responsible for the higher amount of AgNP sorption in the wetland soil and WTR since only half of the total AgNPs in solution were removed with sand particles in the wetland soil (Figure 2(b)). However, the trend correlates well with the increase in carbon con- 
(a)

Silt Loam Soil

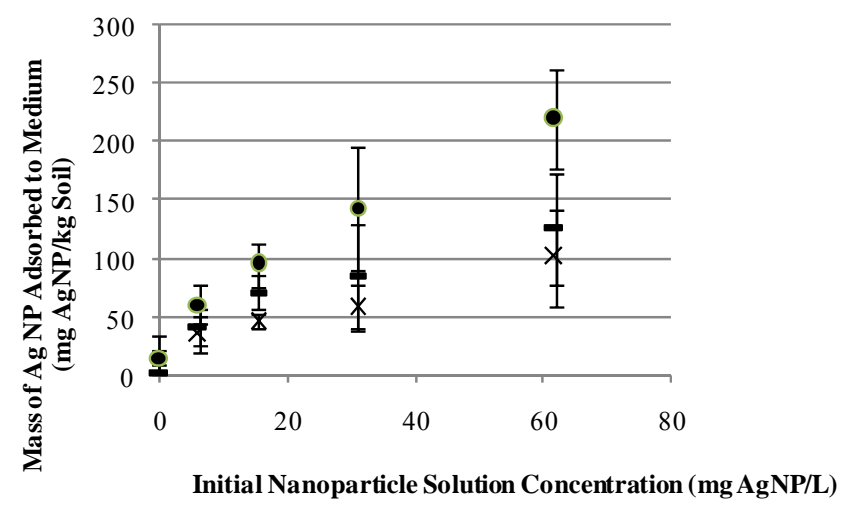

(b)

Wetland Soil

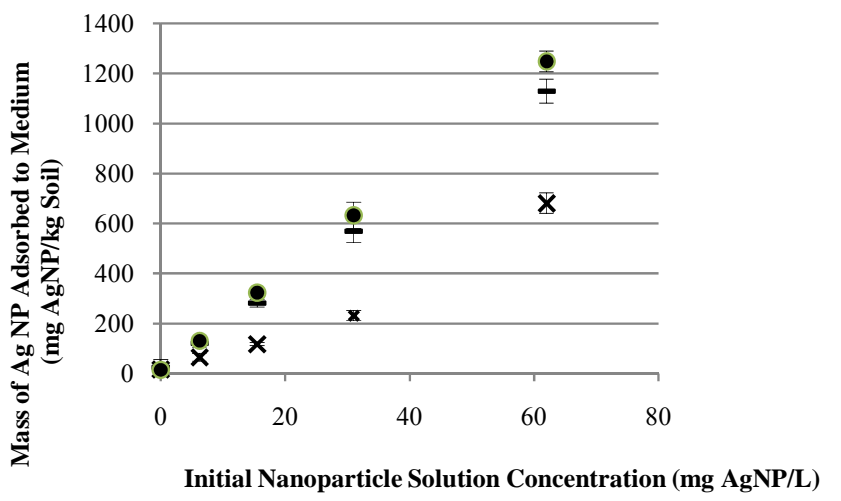

$\times$ AgNP adsorbed to sand*

- AgNP adsorbed to silt and sand

- $\mathrm{AgNP}$ adsorbed to sand, silt, and clay

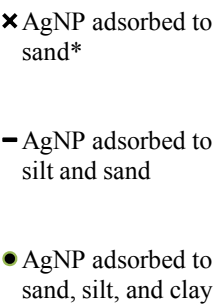

- AgNP adsorbed to sand, silt, and clay

(c)

Water Treatment Residual
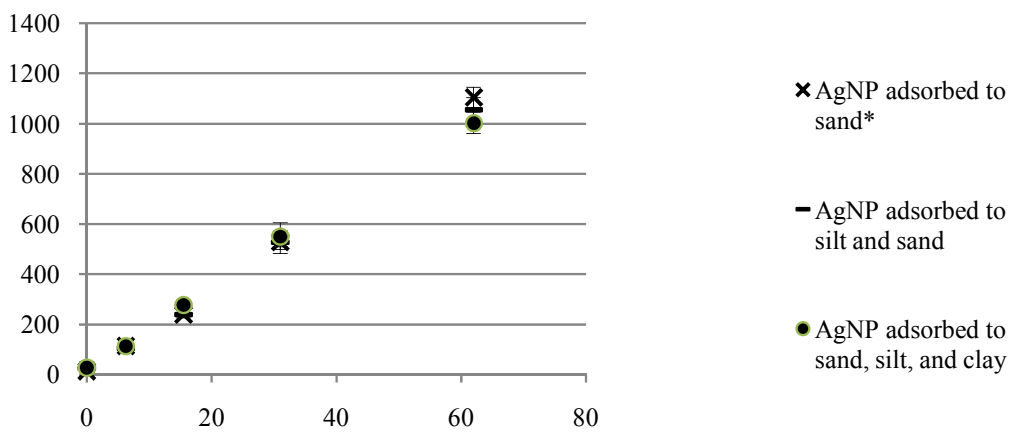

- AgNP adsorbed to sand, silt, and clay

Initial Nanoparticle Solution Concentration (mg AgNP/L)

Figure 2. Silver nanoparticle (AgNP, $10 \mathrm{~nm}$ monodispersed) adsorption to three media (a) silt loam soil, (b) wetland soil, and (c) water treatment residual (WTR). Each data point is the average of three trials, with vertical error bars indicating standard deviation. The three curves on each graph indicate nanoparticles adsorbed to different size classes of soil. "AgNP adsorbed to sand" was measured from the solution concentration after $30 \mathrm{~s}$ (approximate time for sand to settle), “AgNP adsorbed to silt and clay" was measured from the solution concentration after 2 hours (approximate time for silt to settle, and “AgNP adsorbed to all media” was measured from the solution concentration after centrifugation (only dissolved nanoparticles in solution).

tent. The wetland soil has the highest carbon content and showed no reduction in ability to remove AgNP. The WTR showed a slight reduction and had lower carbon content, while the silt loam soil had the lowest amount of carbon and was the least capable of removing AgNPs
(Tables 1 and 2, Figure 2(a)). Recently, researchers found that dispersion and toxicity of AgNP were dependent on the amount of humic acid present [46]. At high humic acid concentrations $(>20 \mathrm{mg}$ total organic carbon/L), significant aggregation of AgNPs was ob- 
Table 2. Percentage of the total silver nanoparticles (AgNP) adsorbed by each medium at each initial solution concentration. This was calculated from the average difference between the initial solution concentration and the final (equilibrium) solution concentration.

\begin{tabular}{cccc}
\hline & \multicolumn{3}{c}{ Percentage of AgNP Adsorbed } \\
\hline $\begin{array}{c}\text { Initial AgNP Solution } \\
\text { Concentration }\end{array}$ & Silt Loam Soil & Wetland Soil & WTR \\
\hline & $\%$ & $\%$ & $\%$ \\
\hline $6 \mathrm{mg} \mathrm{AgNP} / \mathrm{L}$ & 49 & 100 & 93 \\
$15 \mathrm{mg} \mathrm{AgNP} / \mathrm{L}$ & 31 & 100 & 90 \\
$30 \mathrm{mg} \mathrm{AgNP} / \mathrm{L}$ & 16 & 100 & 89 \\
$60 \mathrm{mg} \mathrm{AgNP} / \mathrm{L}$ & 18 & 100 & 81 \\
\hline
\end{tabular}

served. When studying the relative risk ratios for different metallic nanomaterials other researchers found AgNPs pose a greater environmental risk than either $\mathrm{TiO}_{2}$ or $\mathrm{ZnO}$ nanoparticles, which highlights the importance of studying their fate in the environment [47]. However, they also note that their data overestimates the risk to the terrestrial environment, because in ecotoxicity studies there is an assumption that metallic silver is present, when in fact, other studies have shown that often AgNPs are converted to $\mathrm{Ag}_{2} \mathrm{~S}$ during wastewater treatment [4850] and as such are much less soluble and therefore less toxic. Aggregation size was not measured in the data reported in this research, nor was the form of $\mathrm{Ag}$ after equilibration. In Figure 2, all of the removal of AgNPs from the solution is represented as adsorption to the media. Aggregation of AgNPs and settling from solution is not distinguished from adsorption, so adsorption amounts may be inflated. Future research that images the particles and characterizes the adsorption to the media would help determine this.

\subsection{Lab-Scale Constructed Wetland Experiment}

The purpose of the lab-scale constructed wetlands was to examine the toxicity of AgNPs to zebrafish living in a pseudo-natural environment rather than an aseptic, unnatural environment of a petri dish. As the results of the sorption experiment indicate, other environmental factors may impact the fate of AgNPs that enter an ecosystem, potentially rendering them less toxic or simply removed from the environment.

The results of this experiment are inconclusive but do shed light on the impact that environmental factors have on the fate of AgNPs. Fish mortality (Figure 3) only occurred in the positive control treatment $(15 \mathrm{mg} / \mathrm{L} \mathrm{Ag}$ $\mathrm{NO}_{3}$ ) (where in two out of the three weeks, two of the five fish did not survive to the end of the seven day experiment) and in the negative control (where one fish during one of the three weeks did not survive to the end of the experiment). There was no mortality in any of the

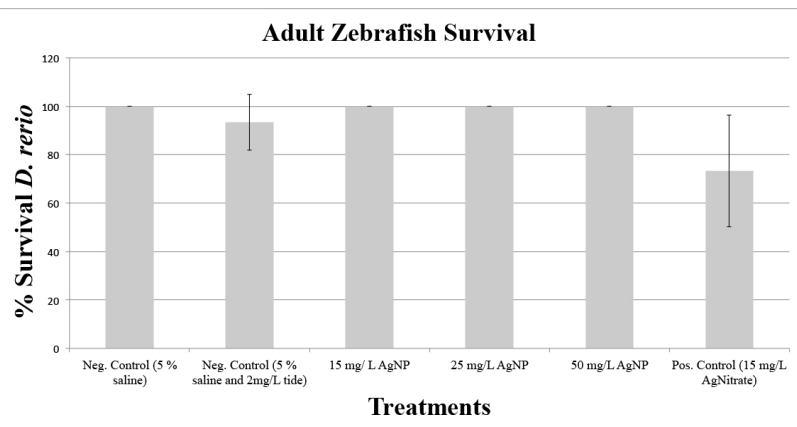

Figure 3. Adult zebrafish survival expressed as a \% of fish surviving after 7 day exposure. Each bar is the average of three trials of 5 fish ( 2 male, 3 female) per lab-scale constructed wetland. Error bars indicate standard deviation; Kruskal-Wallis test gave a p-value of 0.134 between treatments.

AgNP treatments. At first, this data made sense in light of the sorption experiments explained above. The wetland soil had been shown to be able to remove AgNPs from water, so when analyzing the soil of the constructed wetland after the seven-day exposure, it was expected that it would contain AgNPs. However, after digesting the soil at three depth levels, there were no AgNPs measured at any depth (data not shown). Additionally, the daily water samples taken from the middle of the bucket also did not contain AgNPs (data not shown). If the AgNPs were not in the circulating water or in the soil, the conclusion was drawn that the dispersant (Tide detergent) may not have been strong enough to keep the AgNPs dispersed, and the AgNPs may have aggregated and sunk to the bottom of the bucket and stayed in the layer of pebbles. Preliminary trials indicated that the $2 \mathrm{ml}$ Tide/L could keep AgNP in solution, although not as well as at higher concentrations. However, this level was also considered the detergent level where fish may absorb twice the amount of chemicals than they would normally absorb [51]. Tide was chosen as the dispersing agent in this study because it not only acted as a dispersant, but also is a likely way for AgNP to enter the environment through residential laundry.

Other research has shown that AgNPs aggregate in saline solutions [52], which support this conclusion. There was no feasible way found to measure the AgNPs in that layer of pebbles and confirm the conclusion. Recent research is beginning to focus on the fate of nanoparticles in a more natural setting, such as the study reported here. Reference [53] found that plants in a system could help decrease the toxicity of AgNPs because plants release dissolved organic matter which can bind with $\mathrm{Ag}$ ions. In a freshwater system, researchers found that sediments accumulated most of the ceria nanoparticles used in their aquatic system [54]. Additionally other researchers suggest that the chemistry of the nanoparticle capping agent plays an important role in the fate and transport of 
AgNPs and environmental factors such as $\mathrm{pH}$, ionic strength, and electrolyte composition can help predict the fate and transport of AgNPs [55]. Their data showed that positively charged branched polyethyleneimine stabilized AgNPs would most likely have limited mobility in soils, groundwater, and other environments, but sterically stabilized polyvinylpyrrolidone AgNPs may have the greatest potential for mobility and transport. Another recent study indicated that in a sandy loam soil AgNP concentrations eight times greater than $\mathrm{AgNO}_{3}$ concentrations were needed to induce significant reproductive toxicity in earthworms [56]. A study such as the one reported here, although it investigates only a small fraction of the questions still remaining regarding the fate of nanoparticles in the environment provides valuable new information to help guide future studies. Some researchers [47] do not lament the idea that each nanomaterial may react differently depending on the material and the environmental properties and conditions, but instead they reinforce the importance of continuing to study these materials under many different conditions.

Although the lab-scale constructed wetland experiment did not lead to conclusive results regarding the fate of nanoparticles in this environment, it did indicate that the toxicity levels shown in laboratory conditions are not the same as in a more natural environment. Thus the need for similar experiments simulating natural environments is underscored. Simple, inexpensive experimental designs such as this can be implemented to investigate parameters that impact AgNP fate and biotoxicity. Simulated natural environments may prove useful in determining the mechanism of AgNP toxicity to fish. Is direct exposure to suspended AgNPs more or less toxic than dietary exposure to algae or zooplankton that has previously internalized nanoparticles? This question is especially relevant in light of the recent observation that a wide variety of living organisms do take AgNPs out of the water column [57]. Additionally, desorption experiments investigating how tightly bound AgNPs are to environmental media will help elucidate the effectiveness and lifetime of various media in a constructed wetland setting. Preliminary trials have indicated that AgNPs are bound most tightly to the wetland soil, followed by the silt loam soil, and least tightly to the WTR (data not shown), but further research is necessary to investigate this further. As is suggested by multiple groups of researchers $[16,58$, and others], a multidisciplinary approach is crucial to understanding nanoparticle risks in the environment and will involve collaborations between chemists, biologists, toxicologists, ecologists, engineers, and environmental scientists.

\section{Conclusions}

The results of the constructed wetland study indicate that silver nanoparticles appear to aggregate in a salt solution rendering them less toxic to zebrafish than would be expected from previous studies using silver nanoparticles and zebrafish in a pure media. This research did not measure the size of the nanoparticles after they were added to the lab-scale constructed wetland so the aggregation of the nanoparticles cannot be known for sure, but the lack of mortality in the zebrafish and the absence of silver nanoparticles in the water media and wetland soil after nanoparticle addition indicates that the particles most likely sank to the bottom of the buckets. More importantly, the sorption studies provide evidence that soil and water treatment residuals have the ability to remove silver nanoparticles from wastewater. This means that natural and constructed wetlands could be sinks for silver nanoparticles, removing them from wastewater. Using water treatment residuals in a constructed wetland would be a beneficial reuse of a waste product that would otherwise need to be disposed of. It is important to remember that after the silver nanoparticles are removed from the water by sorption to soil or other media, they still remain in the environment adsorbed to the media. Further studies are needed to investigate how tightly and for how long the silver nanoparticles are retained by soil and water treatment residuals. These desorption studies would shed light on the long-term sustainability of a wetland designed to remove nanoparticles and the kind of engineering that would be needed to best manage constructed wetlands.

\section{Acknowledgements}

The authors thank the Wisconsin Lutheran College Faculty Development committee for support of this research. They also wish to thank Michael Reep, Amanda Wagner, Krystal Weishaar, and Benjamin Tellier for their contributions to the preliminary experimental designs and test trials.

\section{REFERENCES}

[1] WHO: World Health Organization, "Small-scale Water Supplies in the pan-European Region," United Nations Economic Commission for Europe, 2010.

[2] T. Brick, B. Primrose, R. Chandrasekhar, S. Roy, J. Muliyil, G. Kang, "Water Contamination in Urban South India: Household Storage Practices and Their Implications for Water Safety and Enteric Infections," Journal of Hygiene and Environmental Health, Vol. 207, No. 5, 2004, pp. 473-480.doi:10.1078/1438-4639-00318

[3] R. B. Levin, P. R. Epstein, T. E. Ford, W. H. Harrington, E. Olson, E. G. Reichard, "U.S. Drinking Water Challenges in the Twenty-First Century," Environmental Health Perspectives, Vol. 100, 2002, pp. 43-52. doi:10.1289/ehp.02110s143

[4] A. J. Jowet, "China's Water Crisis," The Geographical 
Journal, Vol. 152, No. 1, 1986, pp. 9-18. doi: $10.2307 / 632934$

[5] P. Vonlanthen, D. Bittner, A. G. Hudson, K. A. Young, R. Muller, B. Lundsgaard-Hansen, D. Roy, S. Di Piazza, C. R. Largiader and O. Seehausen, "Eutrophication Causes Speciation Reversal in Whitefish Adaptive Radiations", Nature, Vol. 482, 2012, pp. 357-362. doi:10.1038/nature10824

[6] S. S. Kaushal, W. M. Lewis Jr., and J. H. McCutehan Jr., "Land Use Change and Nitrogen Enrichment of a Rocky Mountain Watershed," Ecological Applications, Vol. 16, No. 1, 2006, pp. 299-312. doi:10.1890/05-0134

[7] J. Fawell and M. J. Nieuwenhuijsen, "Contaminants in Drinking Water," British Medical Bulletin, Vol. 68, No. 1, 2003, pp. 199-208. doi:10.1093/bmb/ldg027

[8] S. N. Levine and D. W. Schindler, "Influence of Nitrogen to Phosphorus Supply Ratios and Physicochemical Conditions on Cyanobacteria and Phytoplankton Species Composition in the Experimental Lakes Area, Canada," Canadian Journal of Fisheries and Aquatic Sciences, Vol. 56 , No. 3, 1999, pp. 451-466. doi:10.1139/f98-183

[9] D. L. Correll, "The Role of Phosphorus in the Eutrophication for Receiving Waters: A Review," Journal of Environmental Quality, Vol. 27, No. 2, 1998, pp. 261-266. doi:10.2134/jeq1998.00472425002700020004x

[10] T. C. Daniel, A. N. Sharpley, and J. L. Lumunyon, "Agricultural Phosphorus and Eutrophication: A Symposium Overview," Journal of Environmental Quality, Vol. 27, No. 2, 1998, pp. 251-257. doi:10.2134/jeq1998.00472425002700020002x

[11] E. G. Srinath and S. C. Pillai, "Phosphorus in Sewage, Polluted Waters, Sludges, and Effluents," The Quarterly Review of Biology, Vol. 41. No. 4, 1966, pp. 384-407. doi:10.1086/405158

[12] C. N. Sawyer, H. B. Gotaas, and J. B. Lackey, "Factors Involved in Disposal of Sewage Effluents to Lakes," Sewage and Industrial Wastes, Vol. 26, No. 3, 1954, pp. 317-328.

[13] S. K. Liehr, "Natural Treatment and Onsite Processes," Water Environment Research, Vol. 77, No. 6, 2005, pp. 1389-1424. doi: $10.2175 / 106143005 X 54416$

[14] UN, "Waste-Water Treatment Technologies: A General Review," Economic and Social Commission for Western Asia, New York, 2003.

[15] U. Mander and P. D. Jenssen Eds., "Constructed Wetlands for Waste Water Treatment in Cold Climates," WIT Press, Southampton, 2002.

[16] E. S. Bernhardt, B. P. Colman, M. F. Hochella, Jr., B. J. Cardinale, R. M. Nisbet, C. J. Richardson, and L. Yin, "An Ecological Perspective on Nanomaterial Impacts in the Environment," Journal of Environmental Quality, Vol. 39, No. 6, 2010, pp. 1-12. doi:10.2134/jeq2009.0479

[17] A. B. A. Boxall, M. A. Rudd, B. W. Brooks, D. J. Caldwell, K. Choi, S. Hickmann, E. Innes, K. Ostapyk, J. P. Staveley, T. Verslycke, G. T. Ankley, K. F. Beazley, S. E.
Benlanger, J. P. berninger, P. Carriquiriborde, A. Coors, P. DeLeo, S. D. Dyer, J. F. Ericson, J. Gagne, J. P. Biesy, T. Gouin, L. Hallstrom, M. V. Karlsson and D. G. J. Larsson, "Pharmaceuticals and Personal Care Products in the Environment: What Are the Big Questions?" Environmental Health Perspectives, Vol. 120, No. 9, 2012, pp. 1221-1229. doi:10.1289/ehp.1104477

[18] S. Rodrigues-Mozaz and H. S. Weinberg, "Meeting Report: Pharmaceuticals in Water-An Interdisciplinary Approach to a Public Health Challenge," Environmental Health Perspectives, Vol. 118, No. 7, 2010, pp. 1016-1020. doi:10.1289/ehp.0901532

[19] J. Fabrega, S. N. Luoma, C. R. Tyler, T. S. Galloway and J. R. Lead, "Silver Nanoparticles: Behaviour and Effects in the Aquatic Environment," Environmental International, Vol. 37, No. 2, 2011, pp.517-531. doi:10.1016/j.envint.2010.10.012

[20] A. M. Comerton, R. C. Andrews and D. M. Bagley, "Practical Overview of Analytical Methods for Endocrine-Disrupting Compounds, Pharmaceuticals, and Personal Care Products in Water and Wastewater," Philisophical Transacations: Mathematical, Physical, and Engineering Sciences, Vol. 367, No. 1904, 2009, pp. 3923-3939.

[21] C. G. Daughton and T. A. Ternes, "Pharmaceuticals and Personal Care Products in the Environment: Agents of Subtle Change?" Environmental Health Perspectives, Vol. 107, 1999, pp. 907-938. doi:10.1289/ehp.99107s6907

[22] N. B. Golovina and L. M. Kustov, "Toxicity of Metal Nanoparticles with a Focus on Silver," Mendeleev Communications, Vol. 23, No. 2, 2013, pp. 59-65. doi:10.1016/j.mencom.2013.03.001

[23] C. You, C. Han, X. Wang, Y. Zheng, Q. Li, X. Hu and H. Sun, "The Progress of Silver Nanoparticles in the Antibacterial Mechanism, Clinical Application, and Cytotoxicity," Molecular Biology Reports, Vol. 39, No. 9, 2012, pp. 9093-9201. doi:10.1007/s11033-012-1792-8

[24] K. Kulthong, S. Srising, K. Boonpavanitchak, W. Kangwansupamonkon and R. Maniratanachote, "Determination of Silver Nanoparticle Release from Antibacterial Fabrics into Artificial Sweat," Particle Fibre Toxicology, Vol. 7, 2010, pp. 8. doi:10.1186/1743-8977-7-8

[25] B. Karn, T. Kuiken and M. Otto, "Nanotechnology and in Situ Remediation: A Review of the Benefits and Potential Risks," Environmental Health Perspectives, Vol. 117, No. 12, 2009, pp. 1823-1831.

[26] M. Yousefian and B. Payam, "Effects of Nanochemical Particles on Some Histological Parameters of Fish," Advances in Environmental Biology, Vol. 6, No. 3, 2012, pp. 1209-1215.

[27] F. Gagne, C. Andre, R. Skirrow, M. Gelinas, J. Auclair, G. van Aggelen, P. Turcotte and C. Gagnon, "Toxicity of Silvernanparticles to Rainbow Trout: a Toxicogenomic Approach," Chemosphere, Vol. 89, No. 5, 2012, pp. 615-622. doi:10.1016/j.chemosphere.2012.05.063

[28] S. W. Kim and Y. J. An, "Effect of $\mathrm{ZnO}$ and $\mathrm{TiO} 2$ Nanoparticles Preilluminated with UVA and UVB light on 
Escherichia coli and Bacillus subtilis," Applied Microbiology and Biotechnology, Vol. 95, No. 1, 2012, pp. 243-253.doi:10.1007/s00253-012-4153-6

[29] D. A. Cowart, S. M. Guida, S. Ismat and A. G. Marsh, "Effects of Ag Nanoparticles on Survival and Oxygen Consumption of Zebrafish Embryos, Danio rerio," Journal of Environmental Science and Health, Part A: Toxic/Hazardous Substances and Environmental Engineering, Vol. 46, No. 10, 2011, pp. 1122-1128.

[30] D. Stampoulis, S. K. Sinha and J. White, "Assay-Dependent Phytotoxicity of Nanoparticles to Plants," Environmental Science and Technology, Vol. 43, No. 24, 2009, pp. 9473-9479.

doi:10.1021/es901695c

[31] R. J. Griffit, J. Luo, J. Gao, J. C. Bonzongo and D. S. Barber, "Effects of Particle Composition and Species on Toxicity of Metallic Nanomaterials in Aquatic Organisms," Nanomaterials in the Environment, Vol. 27, No. 9, 2008, pp. 1972-1978. doi:10.1016/j.scitotenv.2006.11.007

[32] K. Y. Yoon, J. H. Byeon, J. H. Park and J. H. wang, "Susceptibility Constants of Escherichia coli and Bacillus subtilis to Silver and Copper Nanoparticles," Science of the Total Environment, Vol. 373, No. 2-3, 2007, pp. 572-575.doi:10.1016/j.scitotenv.2006.11.007

[33] A. S. Barnard and H. Guo, "Nature's Nanostructures," Pan Stanford Publishing, Singapore, 2012.

[34] N. J. Kagengi and A. Thompson, "The Emerging Emphasis on Nanometer-Scale Processes in Soil Environments," Soil Science Society of America Journal, Vol. 75, No. 2, 2011, pp. 333-334. doi:10.2136/sssaj2011.000npsintro

[35] B. K. G. Theng and G. Yuan, "Nanoparticles in the Soil Environment," Elements, Vol. 4, No. 6, 2008, pp. 395-399. doi:10.2113/gselements.4.6.395

[36] J. M. Zook, M. D. Halter, D. Cleveland and S. E. Long, "Disentangling the Effects of Polymer Coatings on Silver Nanoparticle Agglomeration, Dissolution, and Toxicity to Determine Mechanisms of Nanotoxicity," Journal of Nanoparticle Research, Vol. 14, 2012, pp. 1165-1572 doi:10.1007/s11051-012-1165-1

[37] K. R. Reddy, E. M. D'Angelo and W. G. Harris, "Biochemistry of Wetlands," In Handbook of Soil Science, M.E. Sumner (Ed.), CRC Press, 1999.

[38] J. A. Ippolito, K. A. Barbarick and H. A. Elliott, "Drinking Water Treatment Residuals: A Review of Recent Uses," Journal of Environmental Quality, Vol. 40, No.1, 2011, pp. 1-12. doi:10.2134/jeq2010.0242

[39] E. A. Dayton and N. T. Basta, "A Method for Determining the Phosphorus Sorption Capacity and Amorphous Aluminum of Aluminum-Based Drinking Water Treatment Residuals," Journal of Environmental Quality, Vol. 34, No.3, 2005, pp. 1112-1118.doi:10.2134/jeq2004.0230

[40] P. S. Nair, T. J. Logan, A. N. Sharpley, L. E. Sommers, M. A. Tabatabai and T. L. Yuan, "Interlaboratory Comparison of a Standardized Phosphorus Adsorption Procedure," Journal of Environmental Quality, Vol. 13, No. 4, 1984, pp. 591-595. doi:10.2134/jeq1984.00472425001300040016x
[41] H. A. Elliot, G. A. O'Connor, P. Lu and S. Brinton, "Influence of Water Treatment Residuals on Phosphorus Solubility and Leaching," Journal of Environmental Quality, Vol. 31, 2002, pp. 1362-0.69.

[42] G. J. Bouyoucos, "Hydrometer Method Improved for Making Particle Size Analysis of Soils," Agronomy Journal, Vol. 54, No. 5, 1962, pp. 464-465. doi:10.2134/agronj1962.00021962005400050028x

[43] G. W. Gee and J. W. Bauder, "Particle-size Analysis," In A. Klute, Ed., Methods of soil analysis. Part 1. 2nd ed. Agronomy Monograph 9. ASA and SSSA, Madison, WI, 1986, pp. 383-411.

[44] T. M. Benn and P. Westerhoff, "Nanoparticle Silver Released into Water from Commercially Available Sock Fabrics," Environmental Science and Technology, Vol. 42, No. 11, 2008, pp. 4133-4139. doi;10.1021/es7032718

[45] EPA. "Method 3050B (SW-846): Acid Digestion of Sediments, Sludges, and Soils," Revision 2, 1996. http://www.epa.gov/sam/pdfs/EPA-3050b.pdf

[46] J. Gao, K. Powers, Y. Wang, H. Zhou, S.M. Roberts, B. M. Moudgil, B. Kooopman and D. S. Barber, "Influence of Suwannee River Humic Acid on Particle Properties and Toxicity of Silver Nanoparticles," Chemosphere, Vol. 89, No. 1, 2012 pp. 96-101. doi:10.1016/j.chemosphere.2012.04.024

[47] F. Gottschalk, E. Kost and B. Nowack, "Engineered Nanomaterials in Waters and Soils: A Risk Quantification Based on Probabilistic Exposure and Effect Modeling," Environmental Toxicology and Chemistry, 2013, (In Press). doi:10.1002/etc. 2177

[48] B. C. Reinsch, C. Levard, Z. Li, R. Ma, A. Wise, K. B. Gregory, G. E. J. Brown and G. V. Lowry, "Sulfidation of Silver Nanoparticles Decreases Escherichia coli Growth Inhibition," Environmental Science and Technology, Vol. 46, No. 13, 2012, pp. 6992-7000.doi:10.1021/es203732x

[49] R. Kaegi, A. Boegelin, B. Sinnet, S. Zuleeg, H. Hagendorfer, M. Berkhardt and H. Siegrist, "Behavior of Metallic Silver Nanoparticles in a Pilot Wastewater Treatment Plant," Environmental Science and Technology, Vol. 45, No. 9, 2011, pp. 3902-3908. doi:10.1021/es1041892

[50] H. T. Ratte, "Bioaccumulation and Toxicity of Silver Compounds: A Review," Environmental Toxicology and Chemistry, Vol. 18, No. 2, 1999, pp. 89-108. doi:10.1002/etc.5620180112

[51] Lenntech BV, "Detergents Occurring in Freshwater," 2012

http://www.lenntech.com/aquatic/detergents.htm.

[52] G. E. Batley, J. K. Kirby, M. J. McLaughlin, "Fate and Risks of Nanomaterials in Aquatic and Terrestrial Environments," Accounts of Chemical Research, Vol. 46, No. 3, 2013, pp. 854-862.doi:10.1021/ar2003368

[53] J. M. Unrine, B .P. Colman, A. J. Bone, A. P. Gondikas and C. W. Matson, "Biotic and Abiotic Interactions in Aquatic Microcosms Determine Fate and Toxicity of Ag Nanoparticles. Part 1. Aggregation and Dissolution," Environmental Science and Technology, Vol. 46, No.13, 
2012, pp. 6915-6924. doi:10.1021/es204682q

[54] P. Zhang, X. He, Y. Ma, K. Lu, Y. Zhao and Z. Zhang, "Distribution and Bioavailability of Ceria Nanoparticles in an Aquatic Ecosystem Model," Chemosphere, Vol. 89, No. 5, 2012, pp. 530-535. doi:10.1016/j.chemosphere.2012.05.044

[55] A. M. Badawy, T. P. Luxton, R. G. Silva, K. G. Scheckel, M. T. Suidan and T. M. Tolaymat, "Impact of Environmental Conditions ( $\mathrm{pH}$, Ionic Strength, and Electronlyte Type) on the Surface Charge and Aggregation of Silver Nanoparticles Suspensions," Environmental Science and Technology, Vol. 44, No. 4, 2010, pp. 1260-1266. doi:10.1021/es902240k

[56] W. A. Shoults-Wilson, B. C. Reinsch, O. V. Tysusko, P. M. Bertsch, G. V. Lowry and J. M. Unrine, "Role of Particle Size and Soil Type in Toxicity of Silver Nanoparti- cles to Earthworms," Soil Science Society of America Journal, Vol. 75, No. 2, 2011, pp. 365-377. doi:10.2136/sssaj2010.0127nps

[57] D. Cleveland, S. E. Long, P. L. Pennington, E. Cooper, M. Fulton, G. I. Scott, T. Brewer, J. Davis, E. J. Petersen and L. Wood, "Pilot Estuarine Mesocosm Study on the Environmental Fate of Silver Nanomaterials Leached from Consumer Products," Science of the Total Environment, Vol. 421-422, No. 5, 2012, pp. 267-272. doi:10.1002/ieam.5630030316

[58] R. D. Handy and B. J. Shaw, "Ecotoxicity of Nanomaterials to Fish: Challenges for Ecotoxicity Testing," Integrated Environmental Assessment and Management, Vol. 3, No. 3, 2007, pp. 458-460. doi:10.1002/ieam.5630030316 